\title{
Primary hyperoxaluria in Italy: the past 30 years and the near future of a (not so) rare disease
}

\author{
Giorgia Mandrile ${ }^{1}(\mathbb{D})$ Alessandra Pelle ${ }^{2}$ (1) $\cdot$ Veronica Sciannameo ${ }^{3}$ (D) Elisa Benetti ${ }^{4} \cdot$ Maria Michela D'Alessandro $^{5}$. \\ Francesco Emma ${ }^{6}$. Giovanni Montini ${ }^{7,8} \cdot$ Licia Peruzzi $^{9}$ (1) $\cdot$ Michele Petrarulo $^{10} \cdot$ Renato Romagnoli $^{11}$. \\ Corrado Vitale $^{12}$ (1) $\cdot$ Barbara Cellini $^{13} \cdot$ Daniela Giachino $^{14,15}$
}

Received: 29 October 2021 / Accepted: 12 January 2022 / Published online: 26 February 2022

(c) The Author(s) 2022

\begin{abstract}
Background Primary hyperoxalurias (PHs) are rare autosomal recessive diseases of the glyoxylate metabolism; PH1 is caused by mutations in the AGXT gene, PH2 in GRHPR and PH3 in HOGA1.

Methods Here we report the first large multi-center cohort of Italian PH patients collected over 30 years (1992-2020 median follow-up time 8.5 years). Complete genotype was available for 94/95 PH1 patients and for all PH2 $(n=3)$ and PH3 $(n=5)$ patients. Symptoms at onset were mainly nephrolithiasis (46.3\%) and nephrocalcinosis (33.7\%). Median age at onset of symptoms and diagnosis were 4.0 years and 9.9 years, respectively.

Results Fifty-four patients (56.8\%) were diagnosed after chronic kidney disease. Sixty-three patients (66.3\%) developed end stage kidney disease (median age 14.0 years). Twenty-one patients had a kidney-only transplant and, among them, seven had a second kidney transplant combined with liver transplant. A combined kidney-liver transplant was carried out in 29 patients and a sequential kidney-liver transplant was performed in two. In five cases a preemptive liver transplant was performed. Those receiving a liver-only transplant tended to have lower kidney function at last follow-up.

Conclusion Our study of PHs in Italy underlines a considerable diagnostic delay, which has only slightly decreased in recent years. Therefore, we suggest a more extensive use of both metabolic screening among patients with recurrent kidney stones and genotyping, including unambiguous assignment of minor/major allele status in order to promptly begin appropriate
\end{abstract}

Giorgia Mandrile

giorgia.mandrile@unito.it

1 Genetic Unit and Thalassemia Center, San Luigi Gonzaga University Hospital, Regione Gonzole 10, 10043 Orbassano, TO, Italy

2 Medical Genetics Unit, AOU Città della Salute e della Scienza, Turin, Italy

3 Unit of Biostatistics, Epidemiology and Public Health, Department of Cardiac, Thoracic, Vascular Sciences and Public Health, University of Padova, Padua, Italy

4 Pediatric Nephrology, Dialysis and Transplant Unit, Department of Women's and Children's Health, Padua University Hospital, Padua, Italy

5 Pediatric Nephrology Unit, Ospedale dei Bambini, A.R.N.A.S. Civico-G. Di Cristina, Benfratelli Palermo, PA, Italy

6 Division of Nephrology, Department of Pediatric Subspecialties, Bambino Gesù Children's Hospital-IRCCS, Rome, Italy

7 Pediatric Nephrology, Dialysis and Transplant Unit, Fondazione IRCCS Ca' Granda, Ospedale Maggiore Policlinico, Milano, Italy
8 Department of Clinical Sciences and Community Health, University of Milan, Milan, Italy

9 Pediatric Nephrology Unit, "Regina Margherita Department of Children's Diseases", Città della Salute e della Scienza di Torino, Turin, Italy

10 Kidney Stone Laboratory-Chemical-Clinical Laboratory Unit, Azienda Ospedaliera Ordine Mauriziano di Torino, Turin, Italy

11 Liver Transplant Unit, General Surgery 2U, Azienda Ospedaliera Universitaria Città della Salute e della Scienza di Torino, University of Turin, Turin, Italy

12 Nephrology and Dialysis Unit, Azienda Ospedaliera Ordine Mauriziano di Torino, Turin, Italy

13 Department of Medicine and Surgery, University of Perugia, Perugia, Italy

14 Medical Genetic Unit, San Luigi Gonzaga University Hospital, Orbassano, TO, Italy

15 Medical Genetics, Department Clinical and Biological Sciences, University of Torino, Turin, Italy 
treatment. This will be fundamental in order to have access to the new therapies, which are mainly focused on substrate reduction for the oxalate-producing enzymes using RNA-interference.

\section{Graphical abstract}

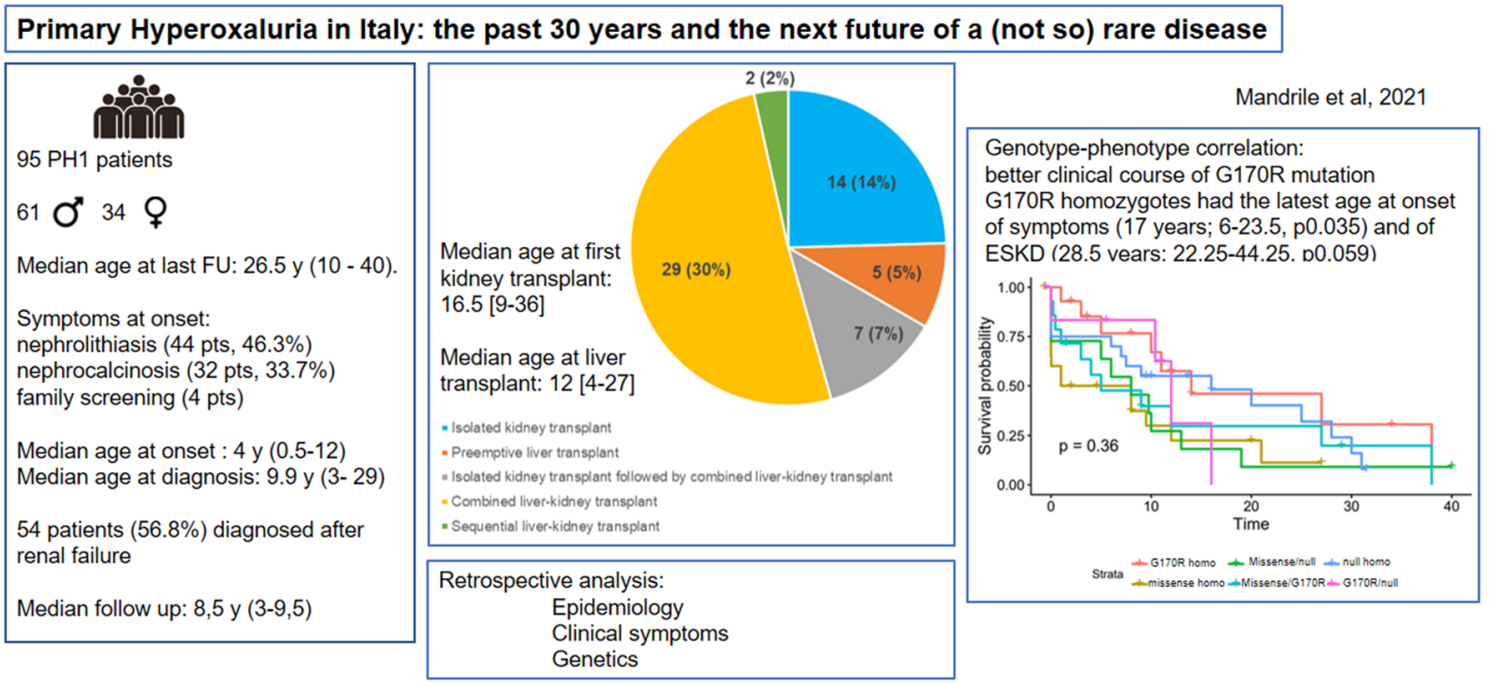

Conclusion: patient charateristic overlapping to published ones.

Relevant diagnostic delay ( $56 \%$ after renal failure, median time for diagnosis $3 y$ )

number of patients lower than expected $\rightarrow$ need for a more extensive use of metabolic and genetic screening in recurrent kidney stones

Keywords Primary hyperoxaluria $\cdot$ Italy $\cdot$ Genotype-phenotype

\section{Background}

Primary hyperoxalurias (PHs) are a group of rare autosomal recessive diseases driven by alterations in the glyoxylate metabolism and characterized by genetic heterogeneity and variable clinical presentation [1]. PH1 is estimated to occur in 1:120,000 live births in Europe [2]. Clinical cohorts evaluate a prevalence ranging from 1:1,000,000 to $3: 1,000,000$ depending on the population studied [2] but population analysis suggests that Primary hyperoxalurias are an order of magnitude more common than determined in clinical cohorts. Summary data obtained from whole genome projects indicate an overall carrier frequency and an inferred prevalence of PHs of 1:70 and 1:58,000, respectively [3]. It is estimated that Primary hyperoxalurias occur in $7-14 \%$ of children with nephrocalcinosis and represent the cause of renal replacement therapy before the age of 15 years in approximately $2 \%$ of patients in European and North American countries [1]. Clinical signs range from severe nephrocalcinosis in the first years of life and progression to diffuse multisystem oxalosis, to recurrent urolithiasis in adult patients [1].

$\mathrm{PH}$ type $1(\mathrm{PH} 1)$, with an overall estimated frequency of $1: 151,000$ (carrier frequency 1:195) [3], is the most common and severe form, eventually leading the majority of patients to end-stage kidney disease (ESKD). PH1 is caused by mutations in the $A G X T$ gene, encoding for the enzyme alanine:glyoxylate aminotransferase (AGT). AGT catalyzes the transamination of alanine and glyoxylate to pyruvate and glycine in the peroxisomal matrix of hepatocytes [4]. AGXT has two common intragenic haplotypes, the Major (Ma) and the minor (mi) alleles (frequency of $80 \%$ and $20 \%$, respectively in the Caucasian population) [5]. Although not pathogenic per se, the mi allele enhances the deleterious effects of several common PH1 mutations [6-8]. Among Caucasians, the most common PH1 mutation, accounting for approximately $30-40 \%$ of alleles, is the p.Gly170Arg (G170R) in the background of the mi haplotype. This variant is characterized by enzyme instability and mistargeting to mitochondria [9], 10. Other recurrent mutations are c.33dupC (11\%) on the Ma haplotype, and p.Ile244Thr (I244T) (6\%) which is present in patients of Spanish or North African origin [11]. Some mutations, such as p.Gly170Arg (G170R) and p.Phe152Ile (F152I), are responsive to pyridoxine (vitamin B6-VB6) supplementation, but at present, the only effective treatment is liver- or combined kidney/liver transplantation [12].

PH type 2 (PH2) is caused by mutations in the gene glyoxylate reductase/hydroxypyruvate reductase (GRHPR), encoding the enzyme responsible for the reduction of 
Table 1 Clinical characteristics of the Italian $\mathrm{PH}$ population

\begin{tabular}{|c|c|c|c|c|}
\hline & PH1 & $\begin{array}{l}\text { PH1 missing data } \\
(\%)\end{array}$ & $\mathrm{PH} 2$ & PH3 \\
\hline$n$ & 95 & & 3 & 5 \\
\hline Males (\%) & $61(64.2)$ & & $2(66)$ & $3(60)$ \\
\hline Females (\%) & $34(35.8)$ & & $1(34)$ & $2(40)$ \\
\hline \multicolumn{5}{|l|}{ Ethnicity } \\
\hline Caucasian & $92(97)$ & & $3(100)$ & $5(100)$ \\
\hline South Asian & $3(3)$ & & & \\
\hline Deceased & $19(20)$ & & 0 & 0 \\
\hline Age at death—years (median [IQR]) & $37.0[19.0,61.0]$ & & & \\
\hline Age at onset of symptoms-years (median [IQR]) & $4.0[0.5,12.0]$ & 6.3 & $13.0[11.0,15.0]$ & $2.0[2.0,2.0]$ \\
\hline Age at diagnosis-years (median [IQR]) & $9.9[3.1,29.0]$ & 5.3 & $28.0[23.0,32.0]$ & $5.5[5.5,11.0]$ \\
\hline Time for diagnosis—years (median [IQR]) & $3.1[0.25,10.0]$ & 6.3 & $13.0[7.5,18.5]$ & $4.0[4.0,8.0]$ \\
\hline Age at last follow up (median [IQR]) & $26.5[10.0,40.8]$ & 1.1 & $25.0[14.5,40.5]$ & $14.0[14.0,16.0]$ \\
\hline Follow up years—years (median [IQR]) & $8.5(3.1-9.5)$ & & $6.0[5.0,10.0]$ & $1.0[1.0,5.0]$ \\
\hline Parental consanguinity (\%) & $15(15.8)$ & 18.9 & 0 & 0 \\
\hline Symptoms at onset (\%) & & 2.1 & & \\
\hline Other affected family members & $4(4.2)$ & 2 & & \\
\hline Hematuria & $1(1.1)$ & & 0 & 0 \\
\hline Acute kidney injury & $1(1.1)$ & & 0 & 0 \\
\hline Chronic kidney disease & $3(3.2)$ & & 0 & 0 \\
\hline Nephrocalcinosis (NC) & $32(33.7)$ & & 1 & 0 \\
\hline Nephrolithiasis (NL) & $44(46.3)$ & & 2 & 5 \\
\hline $\mathrm{NC}+\mathrm{NL}$ & $8(8.4)$ & & 0 & 0 \\
\hline Test requested because of other affected family member & $4(4.2)$ & & 0 & 0 \\
\hline Diagnosis after chronic kidney disease $(\%)$ - total cohort & $54(56.8)$ & 9 & 0 & 0 \\
\hline Patient age at onset $0-3$ years & $23(53.5)$ & 14.0 & & \\
\hline Patient age at onset $3-16$ years & $16(55.2)$ & 3.4 & & \\
\hline Patient age at onset $>16$ years & $14(82.4)$ & 5.9 & & \\
\hline Patients who experienced ESKD & $63(66.3 \%)$ & & $1(34)$ & 0 \\
\hline Age at ESKD—years (median $[\mathrm{IQR}])$ - total cohort & $14.0[5.0,31.5]$ & 33.7 & 48 & \\
\hline Patient age at onset $0-3$ years & $0.7[0.3-10.0]$ & & & \\
\hline Patient age at onset $3-16$ years & $23.0[14.0-33.0]$ & & & \\
\hline Patient age at onset $>16$ years & $40.0[31.0-50.0]$ & & & \\
\hline eGFR at last follow up $\left(\mathrm{ml} / \mathrm{min} / 1.73 \mathrm{~m}^{2}\right)^{\mathrm{a}}$ mean (SD) & $64.2(32.9)$ & 56.8 & $94(53)$ & $76(20)$ \\
\hline \multicolumn{5}{|l|}{ Transplant (\%) } \\
\hline Isolated kidney transplant & $14(14.7)$ & & 1 & 0 \\
\hline Preemptive liver transplant & $5(5)$ & & 0 & 0 \\
\hline $\begin{array}{l}\text { Isolated kidney transplant followed by combined liver-kidney } \\
\text { transplant }\end{array}$ & $7(7)$ & & 0 & 0 \\
\hline Combined liver-kidney transplant & $29(30.5)$ & & 0 & 0 \\
\hline Sequential liver-kidney transplant & $2(2)$ & & 0 & 0 \\
\hline Age at first kidney transplant—years (median [IQR]) & $16.5[9.3,36.3]$ & 43.2 & 52 (1 patient) & \\
\hline Age at second kidney transplant—years (median (IQR)) & $29.0(17.0-45.0)$ & 83.2 & & \\
\hline Age at liver transplant-years (median [IQR]) & $12.0[4.0,27.0]$ & 52.6 & & \\
\hline Pyridoxine response (\%) & & 36.8 & & \\
\hline No & $40(42.1)$ & & & \\
\hline Yes & $20(21.1)$ & & & \\
\hline \multicolumn{5}{|l|}{ Type of mutation (\%) } \\
\hline Homozygotes for a missense mutation (M/M) & $22(23)$ & & & \\
\hline Homozygotes for a null mutation $(\mathrm{N} / \mathrm{N})$ & $21(22)$ & & & \\
\hline G170R homozygotes (G170R/G170R) & $16(16.8)$ & & & \\
\hline Compound heterozygotes $\mathrm{M} / \mathrm{N}$ & $12(12.6)$ & & & \\
\hline Compound heterozygotes M/G170R & $14(14.7)$ & & & \\
\hline Compound heterozygotes N/G170R & $9(9.5)$ & & & \\
\hline
\end{tabular}


Table 1 (continued)

${ }^{a}$ eGFR was calculated by CKD-EPI in adults and by Schwartz equation in pediatric patients

Missing data: percentages are indicated; empty cells indicate that no data are missing

glyoxylate to glycolate and hydroxypyruvate to D-glycerate. PH2 overall estimated frequency is 1:310,000 (carrier frequency 1:279) [3] and accounts for $10 \%$ of PH cases [13]. Most $\mathrm{PH} 2$-associated mutations produce an aberrant protein or affect catalytic activity [14]. Initially considered milder than PH1, a large cohort study recently published by Garrelfs et al. has instead shown kidney impairment in $50 \%$ of patients, of whom $25 \%$ are in ESKD [15].

PH type 3 (PH3), due to mutations in the 4-hydroxy-2-oxoglutarate aldolase 1 (HOGAl) gene (formerly known as DHDPLS), is considered the mildest form of PH. HOGA1 is responsible for the conversion of 4-hydroxy-oxoglutarate to pyruvate and glyoxylate in mitochondria. $\mathrm{PH} 3$ accounts for $8-10 \%$ of PHs [13] and is characterized by recurrent nephrolithiasis, in some cases accompanied by hypercalciuria, that usually decreases with age $[16,17]$. Kidney function is preserved in most patients, although progressive impairment over decades is observed [13] and Martin-Higueras et al. reported that $21.4 \%$ of patients had chronic kidney disease (CKD) stages 2 or higher [18]. PH3 overall estimated frequency is $1: 135,000$ (carrier frequency $1: 185$ ) [3].

The Italian study of Primary hyperoxaluria started in the 1980s and the first reports of $A G X T$ analysis date back to 1998-1999 [19, 20]. In 2008 several clinicians involved in PHs jointly founded OXALEurope, the European Hyperoxaluria Consortium (www.OxalEurope.org), in order to promote a continuous exchange of data, procedures and knowledge among European colleagues, with the main objective of providing $\mathrm{PH}$ patients the same high-level standard of care. With the beginning of $\mathrm{PH}$ genetic analysis in Italy, efforts were made to collect the clinical data of Italian patients and the aim of this paper is to present the state of the art of $\mathrm{PH}$ in Italy.

\section{Methods}

\section{Patients}

PH patients were recruited from January 1992 to July 31st, 2020; the cohort includes 95 PH1 patients (61 males, 64.2\%), $3 \mathrm{PH} 2$ and $5 \mathrm{PH} 3$ patients (Table 1) [IRB approval May 20th, 2014, no. 8616, updated on April 26th, 2021, no. 6492, San Luigi Hospital]. The suspicion of primary hyperoxaluria was based on the patient's history (recurrent or juvenile nephrolithiasis, nephrocalcinosis, ESKD without other causes, kidney biopsy with oxalate deposition); diagnosis workup started with biochemical tests, and genetic analysis was required for diagnosis confirmation. Genotype data were available for 94 out of $95 \mathrm{PH} 1$ patients and for all PH2 $(\mathrm{n}=3)$ and PH3 $(\mathrm{n}=5)$ patients. AGXT analysis was performed by DHPLC until 2009 and by Sanger sequencing of the entire coding region thereafter; MLPA analysis was performed to confirm deletion [21]; the minor/Major haplotype was assigned to each patient. GRHPR analysis was set up in 2007 and HOGAl in 2012 by Sanger sequencing of the entire coding region [22]. The diagnostic workup began, in most patients, with oxalate dosage measurement in urine or plasma (in patients with an eGFR of $30-45 \mathrm{ml}$ per min per $1.73 \mathrm{~m}^{2}$ urinary oxalate is not reliable [2]), or liver biopsy, followed by confirmatory genetic testing. Two cases were diagnosed by kidney biopsy after a transplant failure. Pyridoxine responsiveness was recorded according to the clinician's report. Urinary oxalate results were not included for several patients due to difficulties in harmonizing the data obtained in different laboratories. For patients who were included, biochemical analyses on urine and plasma were performed by gas chromatography. Follow-up time was measured from the onset of symptoms to the last clinical visit or death.

\section{Statistical analysis}

Continuous variables were expressed as median and I-III quartiles as measures of variability; categorical variables were expressed as percentages and absolute numbers. For patients affected by PH1, renal survival was calculated by the Kaplan-Meier method in a multivariate analysis adjusted for age and gender, with patient data censored at last follow-up. The effect of different genotype classes on time to ESKD was estimated using Cox proportional hazard models with adjustment for gender. Proportional hazard assumption was checked using the Grambsch and Therneau test. Continuous variables were expressed as median and I-III quartiles as measures of variability; categorical variables were expressed as percentages and absolute numbers. F test was used to evaluate clinical variables among genotype groups. Median times to ESKD and to symptoms were computed for each genotype using the Kaplan-Meier method and differences were assessed by the log-rank test. All statistical testing was conducted at the 0.05 level. PASW Statistics (version 20) and R (version 2.13) statistical packages were used for analysis. In the genotype-phenotype analysis we grouped $A G X T$ mutations into three classes according to the expected 
Fig. 1 Box plot of age at onset of symptoms in patients receiving kidney and liver transplant, no transplantation, only kidney transplant, only liver transplant

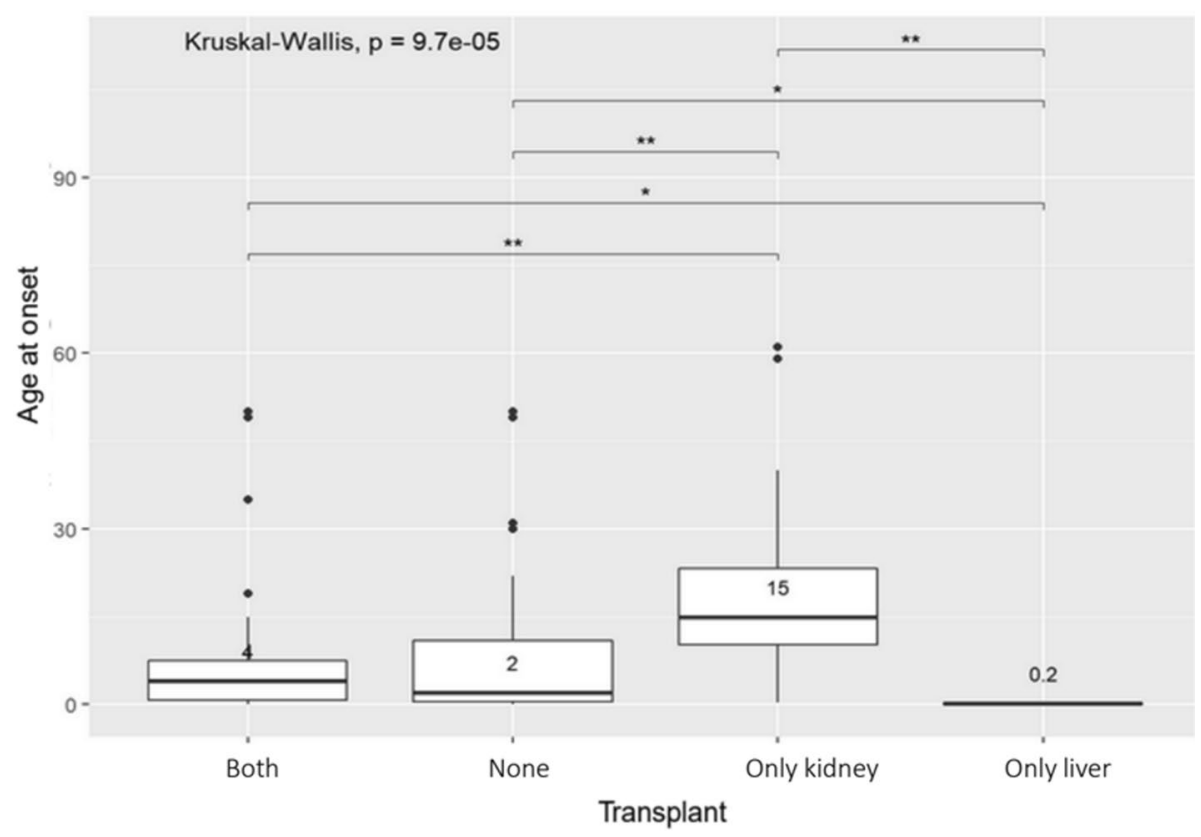

(a)

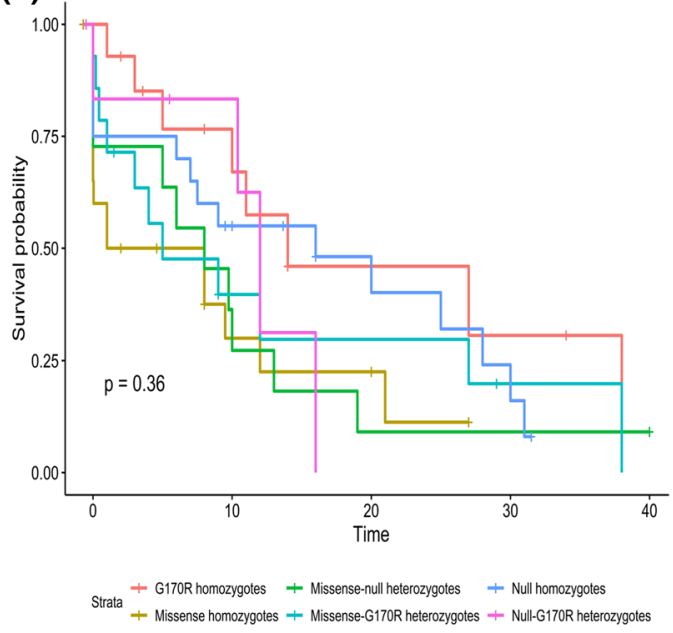

(b)

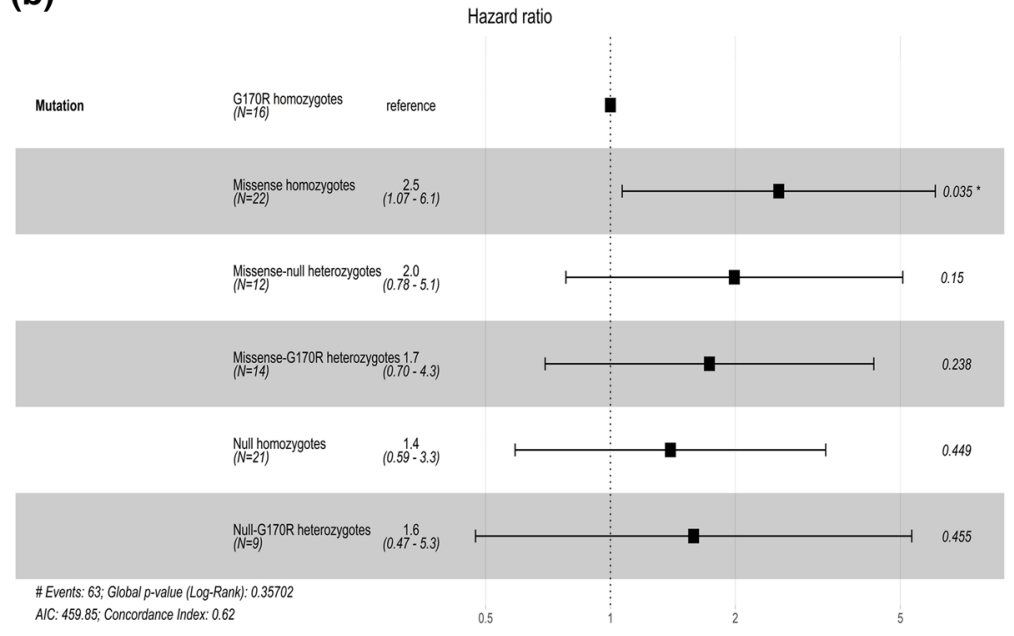

Fig. 2 Kaplan-Meier curve (a) and HR plot (b) of ERKD per type of AGXT mutation (G170R homozygotes in red, missense homozygotes in golden, null homozygotes in dark blue, missense-null hete-

effect on the protein product, as previously published [23]:

1. G170R (T): associated with mitochondrial mistargeting when in cis with the minor allele [9]

2. Other missense (M): missense and in frame ins/del that are unlikely to cause complete lack of protein function.

3. Null (N): exonic deletion, nonsense, frameshift and splice-site mutations, assumed to produce no protein product. rozygotes in green, missense-G170R heterozygotes in light blue, nullG170R heterozygotes in pink) (colour figure online)

\section{Results}

\section{Population characteristics}

Median age of the PH1 cohort at last follow up was 26.5 years (I-III quartile: 10.0, 40.8). Nineteen patients $(20 \%)$ were deceased at the time of analysis. Median age at death was 37.0 years (19.0-61.0). Thirteen patients were lost to follow-up (14\%). Fifty-one patients underwent at least one clinical examination after January 2018. 

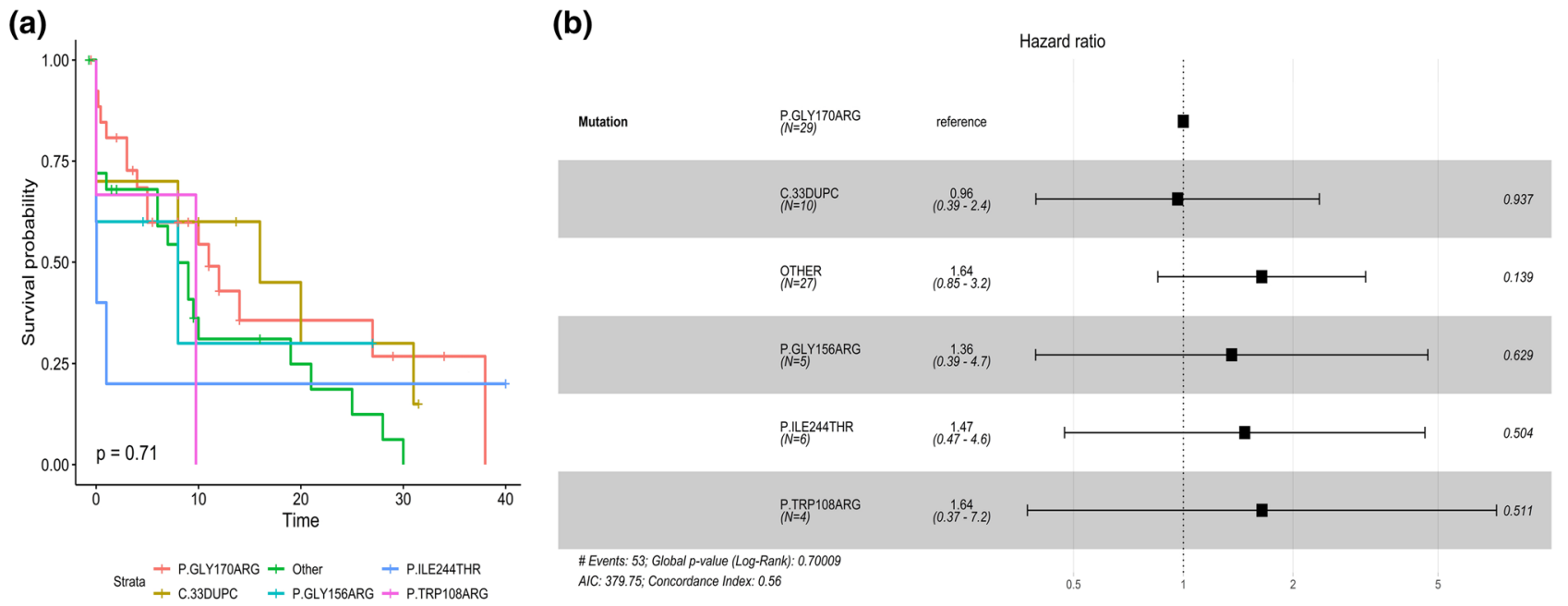

Fig. 3 Kaplan-Meier curve (a) and HR plot (b) of ESKD per most frequent mutations of AGXT in the PH1 cohort

Fifteen patients were born from consanguineous parents (information not available for 18 patients). In 36 cases, a family history of kidney stones was reported. Symptoms at onset were mainly nephrolithiasis (NL, 44 patients, $46.3 \%$ ) and nephrocalcinosis (NC, 32 patients, 33.7\%), consistent with the clinical presentation of $\mathrm{PH}$ patients. Four cases were diagnosed at family screening before the onset of symptoms. Median age at onset and diagnosis were 4.0 years $(0.5-12.0)$ and 9.9 years $(3.1-29.0)$, respectively. Fifty-four patients (56.8\%) were diagnosed after renal failure. Median time to diagnosis was 3.2 years (0.3-10.0). A reduced time to diagnosis was observed for patients diagnosed more recently (after 2010), while no differences were observed if the age at onset of symptoms was considered.

\section{Biochemical analysis}

Median plasma oxalate at diagnosis was $130 \mu \mathrm{mol} / \mathrm{L}$ (24.0-187.0; data not available for 23 patients) and median urinary oxalate was $230 \mu \mathrm{M} / \mathrm{mM}$ creat/24 h (151.0-435.5; data not available for 41 patients). Data regarding glycolate dosage was only available for a small number of patients as it is no longer evaluated in most Italian hospitals. Median plasma glycolate data, available for 27 patients, was $183 \mu \mathrm{mol} / \mathrm{L}$ (125.5-366.0) and median urinary glycolate data, available for 20 patients, was $319 \mu \mathrm{M} /$ $\mathrm{mM}$ creat/24 h (184.5-463.0). Before being replaced by genetic testing (i.e. in the past 15 years), liver biopsy for AGT activity measurement had been performed in 35 of the study patients. Mean residual AGT activity was negligible in 27 out of 35 patients and partial AGT activity was detected in the remaining ones (mean activity: $39 \pm 13 \%$ of the normal AGT activity). The response to VB6 in the form of pyridoxine was assessed in 60 patients and its efficacy was reported in $20(21.1 \%)$. Median VB6 dosage was $10 \mathrm{mg} / \mathrm{kg} / \mathrm{die}(8.5-10.0)$.

\section{End stage kidney disease and transplantation}

At the end of June 2020, 63 patients $(66.3 \%)$ had developed ESKD. Median age at ESKD was 14.0 years (5.0-31.5). No differences between males and females were observed. Twenty-one patients had a kidney-only transplant and, among them, four had a second kidneyonly transplant. In second other cases, the second kidney transplant was combined with liver transplant and one of the patients received two further kidney transplants after their liver transplant; in one case liver transplant was performed together with the third kidney transplant. Median age at first kidney transplant was 16.5 years (9.3-36.3); patients receiving a kidney-only transplant tended to have a higher age at onset compared to those receiving a combined kidney-liver or liver-only transplant (Fig. 1). Combined kidney-liver transplant was performed in 29 patients, while two patients underwent a sequential kidney-liver transplant. Median age at kidney-liver transplant was 12 years (4.0-27.0). In 3 cases a second kidney transplant was performed after the combined kidney-liver transplant, and one patient received a second liver transplant. In five cases a preemptive liver transplant was performed. Those receiving a liver-only transplant tended to have lower renal function at last follow-up. 


\section{Genotype-phenotype correlations}

Most of the $\mathrm{PH}$ patients in our large Italian cohort came from southern Italy and the islands. As reported in the literature, the most common mutation, even in the Italian cohort, was p.Gly170Arg (28\% of the alleles), in 16 patients in homozygosis, in 14 in heterozygosis with a missense mutation, and in 8 with a null mutation. Similar to literature data reported in other populations, the second most frequent mutation was the null c.33dupC mutation. Some mutations were recurrent among apparently unrelated patients coming from the same geographic area. The p.Gly156Arg and p.Ile244Thr mutations were only seen in patients from southern Italy and the islands, therefore, a founder effect or a genetic drift may be hypothesized for these mutations.

$A G X T$ haplotype was consistent with published data in all cases [24].

As expected, homozygotes for the common G170R mutation have the oldest age at onset of symptoms (17 years; 6.0-23.5, p 0.035) and of ESKD (28.5 years; 22.3-44.3, p 0.059) (Fig. 2). G170R homozygotes tend to have a lower prevalence of nephrocalcinosis at diagnosis, as expected. Kidney-only transplant is more frequent among patients carrying at least one G170R mutation (five homozygotes and four heterozygotes). Patients carrying the c.33dupC mutation (seven homozygotes and three compound heterozygotes) tend to have the youngest age at onset and the lowest eGFR at last follow-up, with the highest risk of ESKD (Fig. 3), as observed in a larger cohort [23].

\section{Conclusion}

Here we present the first description of the largest cohort of Italian Primary hyperoxaluria patients collected over 30 years, contributing to delineate the genotypic and phenotypic spectrum of $\mathrm{PH}$ in different populations. The clinical characteristics of our cohort, as expected, largely overlap with those published by the OxalEurope consortium [23] in terms of age at onset of symptoms (3.9 years vs 4.0 years) and median age at diagnosis (8.1 years vs 9.9 years), slightly younger than age at onset (5.2 years) reported by the Rare Kidney Stone Consortium [1]. However, we observed a slightly higher frequency of nephrocalcinosis as a symptom at onset (46.3\% NL-33.7\% NC vs 32\% NL-17\% NC), in line with what was reported by the Rare Kidney Stone Consortium $(30.6 \%$ NC) (Table 1).

It is noteworthy that $56 \%$ of our patients were diagnosed only after renal failure, and that the time from symptoms onset to PH diagnosis is still very long (median 3.2 years), although a trend to a more timely diagnosis has been observed in recent years. Moreover, the number of $\mathrm{PH} 2$ and $\mathrm{PH} 3$ patients in our country was low, thus suggesting a missed diagnosis of these rare diseases, especially in adult patients.

On the basis of exome sequencing data in the general population, Hopp et al. [3] estimated a carrier frequency for $\mathrm{PH} 2$ and PH3 of 1:279 and 1:185, with an expected prevalence of the disease of 1:310,075 and 1:135,866, respectively. This demonstrates that $\mathrm{PHs}$ in general, but $\mathrm{PH} 2$ and $\mathrm{PH} 3$ in particular, are highly underdiagnosed in Italy, most likely due to the milder course of the disease and the less probable evolution to ESKD. Therefore, it is crucial to increase the clinician's awareness of these rare diseases; metabolic screening for all children at first presentation of a kidney stone or nephrocalcinosis, and for all adults with recurrent calcium oxalate kidney stones, could guarantee the best clinical management, as early conservative treatment may delay renal damage, particularly in pyridoxine responsive patients.

Regarding the genotype-phenotype correlation of AGXT mutation classes, we confirmed the better clinical course of patients carrying the G170R mutation. In our population, G170R homozygotes had the oldest age at onset of symptoms (17.0 years; 6.0-23.5, p 0.035) and of ESKD (28.5 years; $22.3-44.3, \mathrm{p} 0.059$ ). Interestingly, the median age at onset in our cohort is considerably higher than what is reported by the OxalEurope consortium (6 years), while the age at ESKD onset did not differ substantially ( 28.5 years vs 33.9 years), although our cohort is affected by a low number of patients. Genotype-phenotype comparison with the Rare Kidney Stone Consortium cohort [1] is not feasible because of different mutation grouping.

In line with previous reports involving European patients, we found several recurrent mutations in addition to G170R. Rumsby et al. demonstrated that Gly170Arg, c.33dupC and p.Ile244Thr are the most common mutations in Europe [25] and these data were confirmed by several other Authors [11, 26]. In agreement with these findings, the c.33dupC and the p.Ile244Thr mutations were found in 14\% (27/190 alleles) and 5.7\% (11/190 alleles) of patients in our cohort, respectively. The p.Ile244Thr mutation was found only in southern Italy and in the islands, as expected from its Spanish origin. (South Italy and the islands belonged to Spanish dominion during the Renaissance). In the same geographic areas, the p.Gly156Arg (12/190-6.3\% of alleles) was also observed, at variance with other Italian regions, suggesting a founder effect.

Several of the mutations observed in the Italian cohort have been studied from a molecular perspective, such as the p.Trp108Arg on the mi allele, found in $6 \%$ of our patients (two homozygotes and four compound heterozygotes). Trp108 is located at the AGT active site and directly interacts with the coenzyme. The p.Trp108Arg variant shows strongly decreased catalytic activity and coenzyme binding affinity, two features suggesting a poor response to 
VB6 supplementation, as found in two of our patients [27]. Another example is represented by mutations affecting Ile56, the consequences of which, at the protein and cellular level, including in particular the response to Vitamin B6, are modulated by the allelic background, consistent with the clinical features of patients (5). These two studies have proved how clinical and molecular data can be combined to improve our comprehension of the phenotype and guide clinicians towards the best therapeutic strategy for $\mathrm{PH} 1$ patients.

Therefore, full AGXT molecular analysis with the reconstruction of the haplotype should always be reported, even when the mutations are found by multigene panel analysis or exome sequencing: it is extremely useful for the clinician because it could help in predicting the functional defect of the disease-causing mutations in synergy with the haplotype [28], thus guiding the therapeutic decision (e.g. VB6 supplementation) and predicting the clinical course. Even if $\mathrm{PH}$ eventually leads to ESKD, genotypes with significant residual enzymatic activity are associated, on average, with a longer disease-free period, and the same mutation in the background of different haplotypes could lead to different clinical courses [8]. Moreover, AGXT genotyping will be fundamental in order to have access to the new therapies developed in recent years, which are mainly focused on substrate reduction for the oxalate-producing enzymes using RNA-interference (RNAi) [29]. In November 2020 the first of the RNAi-based therapies was approved by EMA and the FDA (Lumasiran-Oxlumo ${ }^{\circledR}$ that blocks the production of the enzyme glycolate oxidase, which is involved in the production of glyoxylate. https://www. ema.europa.eu/en/medicines/human/EPAR/oxlumo https:// www.fda.gov/news-events/press-announcements/fda-appro ves-first-drug-treat-rare-metabolic-disorder), while a second one (Nedosiran that inhibits production of the hepatic lactate dehydrogenase (LDH) enzyme, involved in the conversion of glyoxylate to oxalate) is currently being evaluated in clinical trials for all three types of PH (NCT04580420; NCT03847909; NCT04042402; NCT04555486, NCT05001269) [30]. Therefore, it is crucial for PH patients to be properly diagnosed and treated with the most appropriate therapy based on their individual mutations and clinical status [31].

Our study of PHs in Italy underlines the need for a more extensive use of both metabolic screening among patients with recurrent kidney stones and genotyping, including unambiguous assignment of minor/Major allele status. The considerable diagnostic delay, which has only slightly decreased in recent years, may partly explain the overall adverse outcomes in several patients. Limitations of this report include the absence or partial collection of some clinical data, such as details on stone episodes, on VB6 responsiveness and on biochemical dosages, and the lack of a systematic nationwide data collection, all of which hinder accurate prevalence and incidence estimates.

Considering some missing data for patients diagnosed by multigene next generation sequencing not referred to our
Center and an Italian population of around 59.250.000 (Istat data https://www.istat.it/it/archivio/264511), we can hypothesize a PH prevalence of 1.4:1,000,000, in line with most clinical cohorts.

These limitations could be partly overcome by the participation in the OXALEurope database of PH patients, which will be able to provide a better understanding of the diseases in terms of clinical characteristics and prevalence. This would also be a useful tool to reach all PH patients, with important implications for their clinical management (a new therapy is already available for compassionate use in Italy).

Notwithstanding these limitations, our report clearly shows the relevance of this rare disease in Italy and the need to increase awareness of $\mathrm{PH}$ among clinicians, especially in the perspective of the new therapies that will be available in the near future.

Supplementary Information The online version contains supplementary material available at https://doi.org/10.1007/s40620-022-01258-4.

Acknowledgements We would like to thank all the patients and the contributing clinicians for their support. A special thanks to Antonio Amoroso, Mario De Marchi and Martino Marangella, whose work was seminal for PH study in Italy.

\section{Declarations}

Conflict of interests GM and LP participated in an Alnylam advisory Board in May 2020.

Ethical disclosures This study was performed in accordance with the ethical standards, the Declaration of Helsinki and its later amendments; IRB approval May 20th 2014, no. 8616, updated on April 26th 2021, no. 6492, San Luigi Hospital.

Open Access This article is licensed under a Creative Commons Attribution 4.0 International License, which permits use, sharing, adaptation, distribution and reproduction in any medium or format, as long as you give appropriate credit to the original author(s) and the source, provide a link to the Creative Commons licence, and indicate if changes were made. The images or other third party material in this article are included in the article's Creative Commons licence, unless indicated otherwise in a credit line to the material. If material is not included in the article's Creative Commons licence and your intended use is not permitted by statutory regulation or exceeds the permitted use, you will need to obtain permission directly from the copyright holder. To view a copy of this licence, visit http://creativecommons.org/licenses/by/4.0/.

\section{References}

1. Hulton SA (2016) The primary hyperoxalurias: a practical approach to diagnosis and treatment. Int J Surg 36(Pt D):649-654. https://doi.org/10.1016/j.ijsu.2016.10.039

2. Cochat P, Rumsby G (2013) Primary hyperoxaluria. N Engl J Med 369(7):649-658. https://doi.org/10.1056/NEJMra1301564

3. Hopp K, Cogal AG, Bergstralh EJ, Seide BM, Olson JB, Meek AM, Lieske JC, Milliner DS, Harris PC, Rare Kidney Stone C (2015) Phenotype-genotype correlations and estimated carrier 
frequencies of primary hyperoxaluria. J Am Soc Nephrol JASN 26(10):2559-2570. https://doi.org/10.1681/ASN.2014070698

4. Cellini BBM, Montioli R, Paiardini A, Borri Voltattorni C (2007) Human wild-type alanine:glyoxylate aminotransferase and its naturally occurring G82E variant: functional properties and physiological implications. Biochem J 408(1):39-50. https://doi.org/ 10.1042/BJ20070637

5. Coulter-Mackie MB, Lian Q, Applegarth D, Toone J (2005) The major allele of the alanine:glyoxylate aminotransferase gene: nine novel mutations and polymorphisms associated with primary hyperoxaluria type 1 . Mol Genet Metab 86(1-2):172-178. https:// doi.org/10.1016/j.ymgme.2005.05.005

6. Danpure CJ, Jennings PR, Fryer P, Purdue PE, Allsop J (1994) Primary hyperoxaluria type 1: genotypic and phenotypic heterogeneity. J Inherit Metab Dis 17(4):487-499. https://doi.org/10. 1007/BF00711363

7. Danpure CJ (2006) Primary hyperoxaluria type 1: AGT mistargeting highlights the fundamental differences between the peroxisomal and mitochondrial protein import pathways. Biochem Biophys Acta 1763(12):1776-1784. https://doi.org/10.1016/j.bbamcr.2006. 08.021

8. Dindo M, Mandrile G, Conter C, Montone R, Giachino D, Pelle A, Costantini C, Cellini B (2020) The ILE56 mutation on different genetic backgrounds of alanine:glyoxylate aminotransferase: clinical features and biochemical characterization. Mol Genet Metab 131(1-2):171-180. https://doi.org/10.1016/j.ymgme.2020.07.012

9. Danpure CJ, Lumb MJ, Birdsey GM, Zhang X (2003) Alanine:glyoxylate aminotransferase peroxisome-to-mitochondrion mistargeting in human hereditary kidney stone disease. Biochem Biophys Acta 1647(1-2):70-75

10. Cellini B, Lorenzetto A, Montioli R, Oppici E, Voltattorni CB (2010) Human liver peroxisomal alanine:glyoxylate aminotransferase: different stability under chemical stress of the major allele, the minor allele, and its pathogenic G170R variant. Biochimie 92(12):1801-1811. https://doi.org/10.1016/j.biochi.2010.08.005

11. Coulter-Mackie MB, Lian Q, Applegarth DA, Toone J, Waters PJ, Vallance H (2008) Mutation-based diagnostic testing for primary hyperoxaluria type 1: survey of results. Clin Biochem 41(7-8):598-602. https://doi.org/10.1016/j.clinbiochem.2008.01. 018

12. Cochat $\mathrm{P}$, Hulton SA, Acquaviva C, Danpure CJ, Daudon M, De Marchi M, Fargue S, Groothoff J, Harambat J, Hoppe B, Jamieson NV, Kemper MJ, Mandrile G, Marangella M, Picca S, Rumsby G, Salido E, Straub M, van Woerden CS, OxalEurope (2012) Primary hyperoxaluria Type 1: indications for screening and guidance for diagnosis and treatment. Nephrol Dial Transplant 27(5):17291736. https://doi.org/10.1093/ndt/gfs078

13. Singh P, Viehman JK, Mehta RA, Cogal AG, Hasadsri L, Oglesbee D, Olson JB, Seide BM, Sas DJ, Harris PC, Lieske JC, Milliner DS (2021) Clinical characterization of primary hyperoxaluria type 3 in comparison to types 1 and 2: a retrospective cohort study. Nephrol Dial Transplant. https://doi.org/10.1093/ndt/gfab0 27

14. Cregeen DP, Williams EL, Hulton S, Rumsby G (2003) Molecular analysis of the glyoxylate reductase (GRHPR) gene and description of mutations underlying primary hyperoxaluria type 2. Hum Mutat 22(6):497. https://doi.org/10.1002/humu.9200

15. Garrelfs SF, Rumsby G, Peters-Sengers H, Erger F, Groothoff JW, Beck BB, Oosterveld MJS, Pelle A, Neuhaus T, Adams B, Cochat P, Salido E, Lipkin GW, Hoppe B, Hulton SA, OxalEurope C (2019) Patients with primary hyperoxaluria type 2 have significant morbidity and require careful follow-up. Kidney Int 96(6):1389-1399. https://doi.org/10.1016/j.kint.2019. 08.018

16. Beck BB, Baasner A, Buescher A, Habbig S, Reintjes N, Kemper MJ, Sikora P, Mache C, Pohl M, Stahl M, Toenshoff B, Pape
L, Fehrenbach H, Jacob DE, Grohe B, Wolf MT, Nurnberg G, Yigit G, Salido EC, Hoppe B (2013) Novel findings in patients with primary hyperoxaluria type III and implications for advanced molecular testing strategies. Eur J Hum Genet EJHG 21(2):162172. https://doi.org/10.1038/ejhg.2012.139

17. Belostotsky R, Seboun E, Idelson GH, Milliner DS, BeckerCohen R, Rinat C, Monico CG, Feinstein S, Ben-Shalom E, Magen D, Weissman I, Charon C, Frishberg Y (2010) Mutations in DHDPSL are responsible for primary hyperoxaluria type III. Am J Hum Genet 87(3):392-399. https://doi.org/10.1016/j.ajhg. 2010.07.023

18. Martin-Higueras C, Garrelfs SF, Groothoff JW, Jacob DE, Moochhala SH, Bacchetta J, Acquaviva C, Zaniew M, Sikora P, Beck BB, Hoppe B (2021) A report from the European Hyperoxaluria Consortium (OxalEurope) Registry on a large cohort of patients with primary hyperoxaluria type 3. Kidney Int 100(3):621-635. https://doi.org/10.1016/j.kint.2021.03.031

19. Ferrettini C, Pirulli D, Cosseddu D, Marangella M, Petrarulo M, Mazzola G, Vatta S, Amoroso A (1998) Molecular analysis of the AGXT gene in Italian patients with primary hyperoxaluria type 1 (PH1). J Nephrol 11(Suppl 1):18-22

20. Pirulli D, Puzzer D, Ferri L, Crovella S, Amoroso A, Ferrettini C, Marangella M, Mazzola G, Florian F (1999) Molecular analysis of hyperoxaluria type 1 in Italian patients reveals eight new mutations in the alanine: glyoxylate aminotransferase gene. Hum Genet 104(6):523-525. https://doi.org/10.1007/s004390050998

21. Robbiano A, Mandrile G, De Marchi M, Beck B, Baasner A, Murer L, Benetti E, Giachino D (2010) Novel human pathological mutations. Gene symbol: AGXT. Disease: hyperoxaluria. Hum Genet 127(4):468

22. Pelle A, Cuccurullo A, Mancini C, Sebastiano R, Stallone G, Negrisolo S, Benetti E, Peruzzi L, Petrarulo M, De Marchi M, Marangella M, Amoroso A, Giachino D, Mandrile G (2017) Updated genetic testing of Italian patients referred with a clinical diagnosis of primary hyperoxaluria. J Nephrol 30(2):219-225. https://doi.org/10.1007/s40620-016-0287-4

23. Mandrile G, van Woerden CS, Berchialla P, Beck BB, Acquaviva Bourdain C, Hulton SA, Rumsby G, OxalEurope C (2014) Data from a large European study indicate that the outcome of primary hyperoxaluria type 1 correlates with the AGXT mutation type. Kidney Int 86(6):1197-1204. https://doi.org/10.1038/ki.2014.222

24. Williams EL, Acquaviva C, Amoroso A, Chevalier F, CoulterMackie M, Monico CG, Giachino D, Owen T, Robbiano A, Salido E, Waterham H, Rumsby G (2009) Primary hyperoxaluria type 1: update and additional mutation analysis of the AGXT gene. Hum Mutat 30(6):910-917. https://doi.org/10.1002/humu.21021

25. Rumsby G, Williams E, Coulter-Mackie M (2004) Evaluation of mutation screening as a first line test for the diagnosis of the primary hyperoxalurias. Kidney Int 66(3):959-963. https://doi.org/ 10.1111/j.1523-1755.2004.00842.x

26. Monico CG, Rossetti S, Schwanz HA, Olson JB, Lundquist PA, Dawson DB, Harris PC, Milliner DS (2007) Comprehensive mutation screening in 55 probands with type 1 primary hyperoxaluria shows feasibility of a gene-based diagnosis. J Am Soc Nephrol 18(6):1905-1914. https://doi.org/10.1681/ASN.2006111230

27. Oppici E, Montioli R, Lorenzetto A, Bianconi S, Borri Voltattorni C, Cellini B (2012) Biochemical analyses are instrumental in identifying the impact of mutations on holo and/or apo-forms and on the region(s) of alanine:glyoxylate aminotransferase variants associated with primary hyperoxaluria type I. Mol Genet Metab 105(1):132-140. https://doi.org/10.1016/j.ymgme.2011.09.033

28. Cellini B, Montioli R, Voltattorni CB (2011) Human liver peroxisomal alanine:glyoxylate aminotransferase: characterization of the two allelic forms and their pathogenic variants. Biochem Biophys Acta 1814(11):1577-1584. https://doi.org/10.1016/j.bbapap.2010. 12.005 
29. Belostotsky R, Frishberg Y (2020) Novel therapeutic approaches for the primary hyperoxalurias. Pediatr Nephrol. https://doi.org/ 10.1007/s00467-020-04817-8

30. Hoppe B, Koch A, Cochat P, Garrelfs SF, Baum MA, Groothoff JW, Lipkin G, Coenen M, Schalk G, Amrite A, McDougall D, Barrios K, Langman CB (2021) Safety, pharmacodynamics, and exposure-response modeling results from a first-in-human phase 1 study of nedosiran (PHYOX1) in primary hyperoxaluria. Kidney Int. https://doi.org/10.1016/j.kint.2021.08.015

31. Devresse A, Cochat P, Godefroid N, Kanaan N (2020) Transplantation for primary hyperoxaluria type 1 : designing new strategies in the era of promising therapeutic perspectives. Kidney Int Rep 5(12):2136-2145. https://doi.org/10.1016/j.ekir.2020.09.022

Publisher's Note Springer Nature remains neutral with regard to jurisdictional claims in published maps and institutional affiliations. 